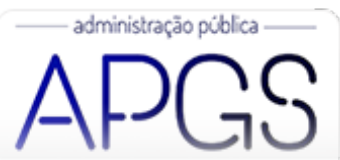

Administração Pública e Gestão Social ISSN: 2175-5787

apgs@ufv.br

Universidade Federal de Viçosa

Brasil

\title{
FORMA E ESPÍRITO DA GESTÃO SOCIAL: o relato de Celso Furtado na brigada internacional do trabalho - lugoslávia 1947
}

Canestri de Oliveira, Lucas; Cardoso Cançado, Airton; Pereira, José Roberto

FORMA E ESPÍRITO DA GESTÃO SOCIAL: o relato de Celso Furtado na brigada internacional do trabalho lugoslávia 1947

Administração Pública e Gestão Social, vol. 12, núm. 4, 2020

Universidade Federal de Viçosa, Brasil

Disponible en: http://www.redalyc.org/articulo.oa?id=351564289003

Esta obra está bajo una Licencia Creative Commons Atribución-NoComercial-SinDerivar 3.0 Internacional. 


\section{FORMA E ESPÍRITO DA GESTÃO SOCIAL: o relato de Celso Furtado na brigada internacional do trabalho - Iugoslávia 1947}

FORM AND SPIRIT OF SOCIAL MANAGEMENT: Celso Furtado's report in the International Labor Brigade - Yugoslavia, 1947

FORMA Y ESPÍRITU DE LA GESTIÓN SOCIAL: el relato de Celso Furtado en la Brigada Internacional del Trabajo - Iugoslavia 1947

Lucas Canestri de Oliveira

Universidade Federal de Lavras, Brasil

Redalyc: http://www.redalyc.org/articulo.oa?

canestri@gmail.com

Airton Cardoso Cançado

Universidade Federal do Tocantins, Brasil

airtoncardoso@yahoo.com.br

José Roberto Pereira

Universidade Federal de Lavras, Brasil

jrobertopereira2013@gmail.com

\section{Resumo:}

O paper analisa os relatos de uma experiência vivida por Celso Furtado em 1947 na Brigada Internacional do Trabalho na Iugoslávia, onde jovens do mundo todo participaram da construção da Omladinska Pruga ("Estrada de Ferro da Juventude"). As questões norteadoras deste trabalho são as seguintes: É possível observar características que hoje são atribuídas a Gestão Social na experiência relatada por Celso Furtado na Iugoslávia? Quais? Qual o ethos da ação? O método compreensivo/analítico aqui utilizado fundamenta-se nas categorias teóricas de "forma" e "espírito" de Max Weber, mais especificamente, consultamos o clássico "A Ética Protestante e o Espírito do Capitalismo". A primeira categoria diz respeito a aspectos institucionais e a segunda categoria a aspectos culturais. Celso Furtado discorre sobre a união nacional e a solidariedade internacional entre jovens (Interesse Bem Compreendido) identificando correntes de opinião (Esfera Pública) capazes de levar adiante o que chama de revolução psicológica (Emancipação).

PalaVras-Chave: Gestão Social, Celso Furtado; Max Weber, Exercício Analítico.

\section{Abstract:}

The paper analyzes the experiences of Celso Furtado in 1947 at the International Labor Brigade in Yugoslavia, where young people from all over the world participated in the construction of the Omladinska Pruga ("Youth Railroad"). The guiding questions of this work are the following: Is it possible to observe characteristics which today are attributed to Social Management in the experience reported by Celso Furtado in Yugoslavia? Which are? What is the ethos of action? The comprehensive or analytical method used here is based on Max Weber's theoretical categories of "form" and "spirit", but specifically, we refer to the classic "Protestant Ethics and the Spirit of Capitalism". The first category refers to institutional aspects and the second category to cultural aspects. Furtado talks about national unity and international solidarity among young people (Well-understood Interest) by identifying currents of opinion (Public Sphere) capable of carrying forward what he calls the psychological revolution (Emancipation).

KeYwORDS: Social Management, Celso Furtado, Max Weber, Analytical Exercise.

\section{Resumen:}

El paper analiza los relatos de una experiencia vivida por Celso Furtado en 1947 en la Brigada Internacional del Trabajo en Yugoslavia, donde jóvenes de todo el mundo participaron en la construcción de la Omladinska Pruga ("Ferrocarril de la Juventud"). Las cuestiones orientadoras de este trabajo son las siguientes: ¿Es posible observar características, que hoy se atribuyen a la Gestión 
Social, en la experiencia o a la práctica relatada por Celso Furtado en Yugoslavia? ¿Qué? ¿Cuál es el ethos de la acción? El método de comprensión y analítico aquí utilizado se fundamenta en las categorías teóricas de "forma" y "espíritu" de Max Weber, pero específicamente, consultamos el clásico "La Ética Protestante y el Espíritu del Capitalismo". La primera categoría se refiere a aspectos institucionales y la segunda categoría a aspectos culturales. Celso Furtado discurre sobre la unión nacional y la solidaridad internacional entre jóvenes (Interés Bien Comprendido) identificando corrientes de opinión (Esfera Pública) capaces de llevar adelante lo que llama de revolución psicológica (Emancipación).

Palabras Clave: Gestión Social, Celso Furtado; Max Weber, Ejercicio Analítico.

\section{INTRODUÇÃo}

O trabalho analisa os relatos de uma experiência vivida pelo jovem Celso Furtado em 1947 na Brigada Internacional do Trabalho na Iugoslávia, onde jovens do mundo todo participaram da construção da Omladinska Pruga ("Estrada de Ferro da Juventude"). Os relatos tratam de diferentes pontos, tais como a forma de gestão dos acampamentos das brigadas, a divisão do trabalho, as relações de gênero, os espaços de diálogo, a relação com o Estado, as expectativas das diferentes opiniões, dentre outros aspectos, num contexto histórico de pós-guerra. Tais relatos foram encontrados em dois livros ("Obra autobiográfica" e "Anos de formação, 1938-1948”). O jovem Celso relata essa experiência pessoal ocorrida aos 27 anos por meio de cartas à família, artigos para revistas e manuscritos.

As questões norteadoras desse trabalho são as seguintes: Quais características, que hoje são atribuídas à Gestão Social, são possíveis identificar na experiência relatada por Celso Furtado na Iugoslávia? Qual o ethos da ação?

O método compreensivo-analítico aqui utilizado fundamenta-se em categorias teóricas de Max Weber, mais especificamente, consultamos o clássico "A ética protestante e o espírito do capitalismo". A inspiração nessa obra de Weber decorre do fato de que o autor demostra por meio das categorias "forma" e "espírito" que, antes da origem do capitalismo enquanto sistema econômico, já houve na história da humanidade tanto formas capitalísticas quanto seu espírito, contudo, Weber conclui que nessas épocas passadas, estes estavam ainda separados (Weber, 2009). Com essa inspiração, busca-se demostrar que é possível encontrar nos relatos de Celso Furtado aspectos que são contemporaneamente abordados por diferentes correntes teóricas sobre Gestão Social. Nesse sentido, os diferentes materiais produzidos pelo jovem intelectual serviram como banco de dados, de onde se buscou extrair situações que ilustram a nosso ver, as categorias teóricas presentes na literatura de Gestão Social contemporânea.

Este trabalho se justifica porque não há uma abordagem de Gestão Social fundamentada em Max Weber. Embora exista uma abordagem que utiliza os conceitos de racionalidade instrumental e racionalidade substantiva, cuja inspiração é Weber, tais fundamentos, quando aplicados à Gestão Social, foram de fato reformulados por Guerreiro Ramos (1981). A abordagem da sociologia compreensiva, fundamentada nos conceitos de forma e espírito, foi muito bem sucedida para interpretar o capitalismo. Imaginamos que tal modelo de análise possa subsidiar uma interpretação do socialismo e contribuir com o campo de pesquisa em Gestão Social.

Os fundamentos da Gestão Social de que este trabalho se valerá para confrontar com as situações relatadas por Celso Furtado estão no livro "Gestão Social: Epistemologia de um paradigma", de Cançado, Pereira e Tenório (2015). Nesse livro os autores apresentam a produção do conhecimento científico a respeito da Gestão Social por meio de uma ampla revisão bibliográfica e definem um grupo de três categorias que sintetiza os fundamentos das diferentes perspectivas que coexistem. São eles: Interesse Bem Compreendido, Esfera Pública e Emancipação.

Este trabalho estrutura-se por um percurso teórico metodológico dividido em quatro momentos. No primeiro momento é realizada uma apresentação do protagonista em questão, o economista Celso Furtado. Essa apresentação abordará apenas a juventude desse intelectual e busca traçar os caminhos que o levaram 
até a brigada internacional do trabalho, foco do nosso interesse. Em seguida introduzimos as categorias de forma e espírito como apresentadas por Max Weber e como estas se relacionam. No terceiro momento apresentamos uma síntese das categorias teóricas da Gestão Social compiladas por Cançado et al. (2015). Por fim, as situações relatadas por Furtado na experiência iugoslava são confrontadas com as categorias da Gestão Social e desdobradas numa resenha analítica e em um quadro síntese como forma e espírito da Gestão Social, onde a primeira categoria diz respeito a aspectos institucionais e a segunda categoria, a aspectos culturais. Furtado discorre sobre a união nacional e a solidariedade internacional entre jovens (Interesse Bem Compreendido) identificando correntes de opinião (Esfera Pública) capazes de levar adiante o que chama de revolução psicológica (Emancipação). Avaliamos que Weber nos autoriza sugerir tal confrontação e formular a seguinte tese: Tanto a forma quanto o espírito da Gestão Social se encontraram naqueles tempos difíceis relatados pelo jovem Celso Furtado, o que desencadeou um caso ancestral ou, no mínimo, um momento de Gestão Social como fenômeno de massa.

\section{O Jovem Celso Furtado}

Celso Furtado adquiriu notoriedade nacional como homem público e economista, foi um estudioso dos problemas organizacionais cujas preocupações conjugam, com originalidade e ética, a teoria e a prática. Nascido em 26 de julho de 1920 em Pombal, na Paraíba, foi estudar ainda na adolescência na capital desse estado e, pouco depois, foi estudar em Recife, capital de Pernambuco. Em 1939 foi para o Rio de Janeiro, onde cursou a faculdade de Direito na Universidade do Brasil, diplomando-se em 1944 (Iglésias, 2014).

O contexto intelectual da época é marcado pela busca da superação de uma ordem arcaica, tanto do ponto de vista institucional quanto cultural. O movimento modernista, iniciado nos anos 1920, na literatura, artes plásticas e música, foi determinante e começou a influenciar a academia. A atividade intelectual consolidase com a inclusão das disciplinas de Sociologia e de Economia num ambiente universitário onde prevaleciam o Direito, a Engenharia e a Medicina, ainda assim, dentro de padrões já superados nos centros criativos da Europa e dos Estados Unidos. No âmbito político, o Estado Novo iniciava uma reforma administrativa, num ambiente cuja compreensão patrimonial é resistente a gestão burocrática (Iglésias, 2014).

Celso Furtado desembarca no Rio de Janeiro no ano de 1940, com 18 anos de idade, obtendo êxito no exame de admissão da faculdade de Direito (D’Aguiar, 2014). Começa a trabalhar como redator auxiliar no periódico Revista da Semana e logo empreende trabalhos jornalísticos. No terceiro ano de faculdade Furtado é aprovado no concurso do Departamento de Administração do Serviço Público, o DASP. "A temática da organização e administração pública monopoliza seu interesse” (D’Aguiar, 2014, p. 16). Nessa época também desperta o interesse de estudar no exterior, tenta uma bolsa para os Estados Unidos, mas não obtém sucesso.

Quando o Brasil entrou na Segunda Guerra Mundial em agosto de 1942, Celso Furtado acabava de fazer 22 anos, havia prestado o tiro de guerra aos 17 em João Pessoa e cogitava a possibilidade de ser convocado. Foi quando decidiu fazer um segundo serviço militar no Centro de Preparação de Oficiais da Reserva (CPOR) e ir para a guerra como oficial. Conciliando os expedientes do quartel, do trabalho e da faculdade, concluiu o curso militar em outubro de 1944, em dezembro do mesmo ano formou-se em Direito e foi convocado para a guerra. "Em 8 de fevereiro de 1945 embarcava no quinto contingente da Força Expedicionária Brasileira (FEB), junto com seis mil soldados, a bordo do General Meigs, com destino a Itália” (D’Aguiar, 2014, p. 18).

$\mathrm{Na}$ experiência da guerra viu na prática a importância da organização e do planejamento para um exército em tempos de guerra. [...] Percebeu também o perigo de se transplantar o modelo de organização militar para uma sociedade democrática. Era essa a pretensão do fascismo (D’Aguiar, 2014, p. 17).

Com 25 anos o segundo tenente da reserva Celso Furtado retorna ao Rio de Janeiro em 17 de setembro de 1945 junto com 1800 combatentes. Retornou decidido a não seguir a profissão de advogado. Aguarda a baixa no Exército, planeja criar uma revista que se chamará "Luta - pela cultura do povo" e chefia a Divisão 
de Organização do Departamento de Serviço Público do Estado do Rio de Janeiro. Dedica-se ao estudo de bibliografias em inglês, francês e espanhol sobre o planejamento governamental e escreve sobre temas variados, principalmente sobre a guerra. Nessa época lê Weber, Marx e Barnes. Retorna às aulas de alemão e torna a pensar em estudos no exterior, na Rússia, Suíça ou na França além de ser "sondado para contrato de trabalho na recém-criada Organização das Nações Unidas (ONU), com sede em Nova York” (D’Aguiar, 2014, p. 22).

Em janeiro de 1947 Celso embarca pela segunda vez para a Europa. Financia sua viagem e permanência de um ano e meio com as economias feitas com o soldo da FEB. Além disso, já estava na França quando o pai lhe comunica que seu trabalho "Trajetória da Democracia na América”, escrito um ano antes, foi agraciado com o Prêmio Franklin Roosevelt promovido pelo Instituto Brasil-Estados Unidos, no valor de 5 mil cruzeiros (D’Aguiar, 2014).

Matricula-se, primeiro como ouvinte, no Institut d'Etudes Politiques, a prestigiada Sciences Po, e nela estuda história do socialismo, marxismo, história das ideias políticas e história dos fatos econômicos. Consegue equivalência de títulos e inscreve-se no doutorado da faculdade de Direito e Ciências Econômicas da Universidade de Paris. "Em um só ano fará o que é praxe fazer em dois ou três: O curso de doutorado e a tese". Sua tese foi defendida em $1^{\circ}$ de junho de 1948, com o tema "Economia Colonial Brasileira" que recebeu a menção "très bien" (D’Aguiar, 2014, p. 23).

Apesar do contexto sócio econômico do pós-guerra ser muito instável, com racionamentos, greves e insurreições, o ambiente intelectual de Paris era dos mais estimulantes (D’Aguiar, 2014,) “Celso menciona a profusão de jornais e revistas acadêmicas, livrarias, cinemas, teatros, e frequenta rodas de brasileiros, sendo os amigos mais chegados o pintor Carlos Scilar e a pianista Anna Stella Schic" (D'Aguiar, 2014, p. 24). Foi com esses amigos que no verão de 1947 passou quarenta dias na Europa Central. Foram ao I Festival Mundial da Juventude, em Praga, que reuniu 200 mil jovens de diversos países. Da Tchecoslováquia foram para a Iugoslávia, onde viveu a experiência na brigada de jovens voluntários que foram ajudar a construir uma estrada de ferro "onde ocorria uma profunda revolução social para vencer o atraso material e cultural" (D'Aguiar, 2014, p. 26). Essa experiência será alvo de nossa análise e nela serão destacadas as características que hoje a teoria normativa atribui à Gestão Social. Na véspera de completar 28 anos, em julho de 1948, Celso Furtado retorna pela segunda vez ao Rio de Janeiro. De acordo com D’Aguiar (2014), encerravam-se os anos de formação e iniciavam-se os anos de afirmação.

\section{Forma E ESPÍRITO DO CAPITALISMO EM MAX WEBER}

A inspiração na teoria de Max Weber, para orientação metodológica deste exercício analítico, decorre do fato de que o autor demostra por meio das categorias forma e espírito que, antes da origem do capitalismo como sistema econômico, já houve na história da humanidade tanto formas capitalísticas quanto seu espírito, contudo, ele conclui, nessas épocas passadas estes estavam ainda separados, ou ainda, se juntos, não representavam o sistema hegemônico (Weber, 2009).

No clássico "A ética protestante e o espírito do capitalismo" Weber (2009) levanta a seguinte questão: Por que o capitalismo surge no ocidente? A resposta apontada pelo autor está no racionalismo peculiar e específico da cultura ocidental. Sua preocupação é desvendar e explicar a gênese e a peculiaridade desse racionalismo e por meio desse enfoque revelar sua forma moderna. $\mathrm{O}$ aspecto central de sua pesquisa é a influência de certas ideias religiosas no desenvolvimento de um ethos econômico. Weber (2009) sugere que o surgimento do moderno espírito da vida econômica deriva da ética racional da ascese protestante, de maneira que esta última permitiu a consolidação da racionalidade instrumental de condução sistemática da vida e de dominação do mundo, "produzindo indivíduos disciplinados, orientados por Deus, racionais e liberados para ganhar dinheiro através da vocação como prova de salvação" (Hartmann, 2014, p. 33). Como esclarece o próprio Weber, a reforma protestante não deu origem ao capitalismo de maneira isolada, mas a ética protestante foi, 
sim, uma mola autopropulsora, devido a sua adequação e afinidade com as formas capitalísticas que já existiam no mundo, dando um impulso nos aspectos qualitativo e quantitativo desse sistema econômico (Weber, 2009; Hartmann, 2014; Schluchter, 2011).

É fundamental ter em vista que a ação racional e o cálculo como base da ação individual não são características exclusivamente ocidentais. Por isso, e nesse sentido, pode-se dizer que formas capitalísticas existiram na China, na Índia, na antiga Babilônia, no Egito, Império Asteca, entre outras civilizações, mas não se tornaram o sistema econômico hegemônico destes lugares (Weber, 2009). Ou seja, embora as formas capitalísticas não tenham se manifestado apenas no sistema capitalista, o mundo não conheceu uma organização racional do trabalho fora do ocidente, mas existiram, sim, outros formatos e Weber cita alguns tipos, como "a economia de abastecimento cívico, o mercantilismo, a política de bem estar social dos príncipes, o racionamento, a regulamentação da vida econômica, o protecionismo e teorias do laissez-faire na China" (Weber, 2009, p. 30). Weber (2009) mostra que é possível seguir as origens e tempos anteriores ao advento do capitalismo, concluindo que como sistema econômico hegemônico, este surgiu na América do Norte e na Europa ocidental e não na China, Índia, Babilônia, etc., pois nestas civilizações faltou o ethos particular, o ascetismo de matriz calvinista, "a mola autopropulsora" ou o espírito do capitalismo, uma vez que pelo mundo inteiro sempre houve comerciantes, atacadistas, varejistas locais ou envolvidos em comércio exterior e financistas. Também há a figura do "aventureiro capitalista", um tipo de empreendedor que "existiu em toda parte, explorando guerras, piratarias e concessões de todo tipo" (Weber, 2009, p. 28). Contudo, todas essas formas eram ainda apenas sugestões, nada que se compara ao sistema capitalista que se consolidou com o espírito do capitalismo.

A aquisição capitalista aventureira tem sido familiar a todos os tipos de sociedade econômica que conheceram o comércio com o uso do dinheiro [...] A diferença não está no grau de desenvolvimento de qualquer impulso de ganhar dinheiro, a auri sacra fames (fome de riqueza) é tão velha quanto a história do Homem [...] Não são os representantes dessa atitude mental a causa do moderno espírito do capitalismo como fenômeno de massa, que é o que interessa saber (Weber, 2009, pp. 53-54).

Weber está argumentando aqui que o racionalismo, a avareza e a fome por riquezas não explicam o surgimento do capitalismo, uma vez que o que interessa saber está, sobretudo, no "elemento irracional subjacente nesta como em qualquer outra concepção de vocação” (Weber, 2009, p. 138). A literatura ascética derivada da Reforma Protestante aprofunda a ideia de que não importa o trabalho, desde que executado racionalmente será algo agradável a Deus, pois atende a seu chamado. Esse ethos:

Gerou a sanção psicológica mediante o conceito de trabalho como vocação, como o melhor meio e, muitas vezes o único, de obter a certeza da graça, interpretando também a atividade empresarial como vocação (Weber, 2009, p. 138).

A atitude mental de buscar o lucro racional e sistemático encontrou sua mais apropriada expressão na empresa capitalista. De acordo com Hartmann (2014, p. 42) "tal ethos profissional encontrou sua forma mais adequada na empresa capitalista moderna", e por sua vez, a empresa capitalista moderna encontrou nesse ethos profissional sua força motriz espiritual. A forma do capitalismo (livre empresa econômica) e o espírito do capitalismo (ética ascética calvinista) podem, portanto, ocorrer separadamente, "os indivíduos que incorporavam o espírito do capitalismo (os burgueses) não faziam parte da aristocracia comercial, com fortunas acumuladas de gerações, mas pequenos industriais emergentes" (Weber, 2009, p. 59). Ou seja, na gênese do capitalismo como sistema econômico, os donos das livres empresas (a aristocracia comercial) formavam o corpo pré-capitalista, uma vez que a utilização racional do capital em empresas estáveis e a organização racional capitalista do trabalho não havia ainda se tornado a força dominante na determinação da atividade econômica.

É preciso destacar que Weber frisa ser a irracionalidade o fator distintivo, e o elemento irracional subjacente a esta concepção de vocação é justamente o ascetismo cristão. Weber (2009) aponta que, de início, o ascetismo dizia respeito ao comportamento de se retirar do mundo para a solidão dos mosteiros, deixando intacto o caráter naturalmente espontâneo da vida laica no mundo. Em decorrência da ética reformada, 
o ascetismo passa a colonizar o mundo da vida, "fechando atrás de si a porta do mosteiro e penetrando justamente naquela rotina de vida diária, com sua metodicidade, para amoldá-la a uma vida laica, embora não para e nem deste mundo" (Weber, 2009, p. 121). Esse tipo de ethos orienta o comportamento nas diferentes dimensões da vida, voltando-se com toda sua força contra o desfrute de tudo o que a vida tem para oferecer, caracteriza-se pela frugalidade, ascese sexual, repúdio ao ócio e até mesmo a prática de esportes, artes cênicas e plásticas, "o homem sobre a terra deve, para ter certeza do estado de graça, trabalhar naquilo que lhe foi destinado, ao longo de toda a sua jornada [...] o repouso dos santos se encontra no outro mundo" (Weber, 2009, pp. 123-124).

Por fim, Weber (2009) argumentava no início do século XX, que já não era mais necessário o suporte de qualquer força religiosa para dar forma ao sistema capitalista. Hoje estamos envoltos na "gaiola de ferro", criada historicamente, ou seja, numa situação onde "a racionalidade técnica, a racionalização da vida, o ganho ou lucro como fim em si mesmo e o indivíduo absorvido pela profissão consolidaram-se como sistema hegemônico" (Hartmann, 2014, p. 42).

\section{Fundamentos da Gestão Social}

Os fundamentos da Gestão Social de que este trabalho se valerá para confrontar com a experiência relatada por Celso Furtado estão no livro "Gestão Social: Epistemologia de um paradigma”, de Cançado et al. (2015). Os autores apresentam a produção do conhecimento científico a respeito da Gestão Social por meio de uma ampla revisão bibliográfica e definem um grupo de três categorias, que sintetiza os fundamentos das diferentes perspectivas que coexistem no debate acadêmico contemporâneo. O objetivo dos autores foi jogar luz sobre uma possibilidade objetiva de construção de um campo de conhecimento científico específico, uma vez que identificam a maturidade teórica para tanto. Segundo os autores, o conteúdo epistemológico sobre o significado da gestão social vem se desenvolvendo desde a década de 1990, avançando no sentido de democratizar os processos de decisão (Cançado, Pereira, \& Tenório, 2015). Os autores contextualizam seu argumento com uma síntese provisória do conceito contemplando as demais características da Gestão Social como tomada de decisão coletiva, ausência de coerção, inteligibilidade, dialogicidade e entendimento esclarecido. Com essas características os autores preparam o caminho para a aproximação teórica.

Em seguida, Cançado et al. (2015) elencam diferentes autores que delinearam o campo da Gestão Social nos últimos anos. A participação é a característica que perpassa toda a discussão. Mesmo em perspectivas diferentes os autores concordam que se não há participação, não há gestão social. Há ainda a incorporação de críticas que o conceito de Gestão Social tem recebido.

Para os autores, a proposição das categorias teóricas da Gestão Social é uma "delimitação feita a lápis", no sentido de ser o começo de um debate que pode redesenhá-lo com os seus desdobramentos (Cançado et al., 2015). Cabe ressaltar que as categorias podem ser consideradas como tipos ideais weberianos, logo, não têm caráter prescritivo, mas sim analítico (Cançado et al., 2015). Na figura 1 estas categorias são colocadas didaticamente em conjunto da seguinte forma: 


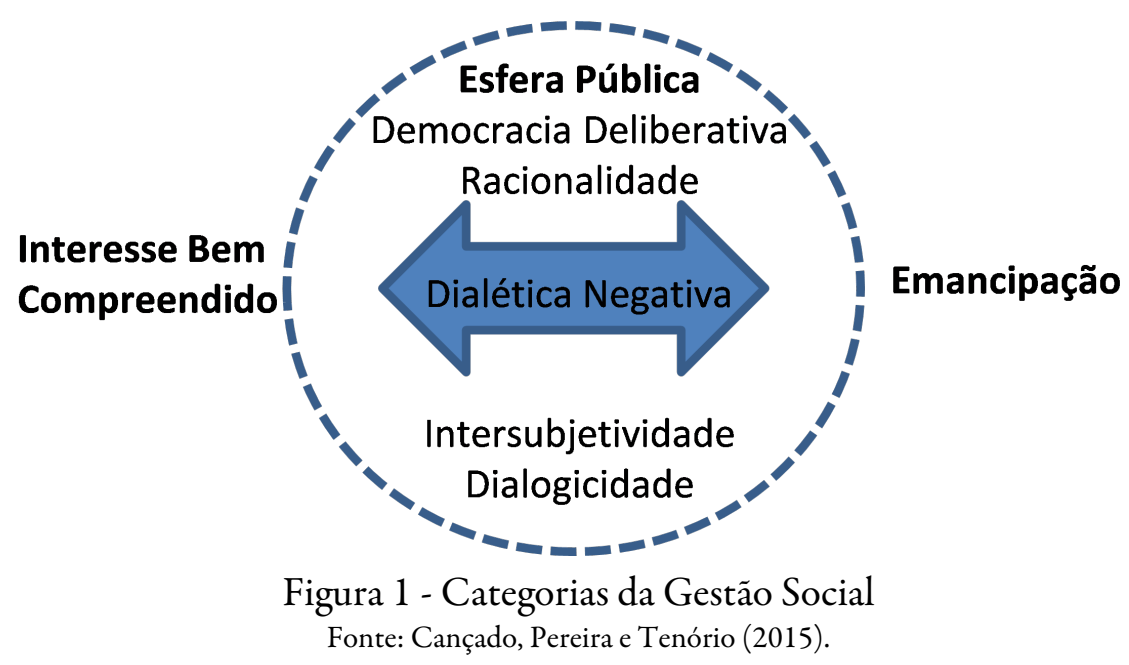

A Gestão Social é caracterizada, portanto, como um processo que se fundamenta em três grandes categorias teóricas que se articulam numa dialética negativa, ou seja, transita do Interesse Bem Compreendido à Esfera Pública e Emancipação e vice-versa. Conforme destacam os autores, o conceito de Interesse Bem Compreendido (IBC) é apresentado por Alexis Tocqueville em 1835 na obra "A Democracia na América" e parte da premissa de que o bem estar coletivo é pré-condição para o bem estar individual. Dessa premissa desdobra-se um princípio moral orientador que diz que até a última instância, ao fazer a defesa dos interesses coletivos, o indivíduo está defendendo seus próprios interesses. A "máxima” de Tocqueville que sintetiza a premissa é: “A virtude é útil” (Cançado et al., 2015).

Em relação à categoria Esfera Pública, os autores expõem seu desenvolvimento até a esfera pública burguesa (Habermas, 2003) e avançam posteriormente para o que eles consideram uma esfera pública ampliada, que consiga aproximar novamente, mas por outra perspectiva, a população da política (Cançado et al., 2015).

A esfera pública não pode ser entendida como uma instituição, nem como uma organização, pois ela não constitui uma estrutura normativa capaz de diferenciar entre competências e papeis, nem regula o modo de pertença a uma organização. [...] A esfera pública pode ser descrita como uma rede adequada para a comunicação de conteúdos, tomadas de posição e opiniões, nela os fluxos comunicacionais são filtrados e sintetizados, a ponto de se condensarem em opinióes públicas enfeixadas em temas específicos. [...] A esfera pública retira seus impulsos da assimilação privada de problemas sociais que repercutem nas biografias particulares. (Habermas, 2003, pp. 92-98).

Cançado et al. (2015) argumentam que esta categoria da Gestão Social deve abarcar os seguintes elementos: Democracia deliberativa, racionalidade, dialogicidade e intersubjetividade. Essas categorias são apresentadas em três momentos da seguinte forma: Primeiramente a democracia deliberativa como processo decisório da Gestão Social; em seguida propõe-se um tipo de racionalidade para a condução da Gestão Social; por fim as comunidades de prática são apresentadas como a dinâmica de interação da Gestão Social na Esfera pública. No âmbito dessa interação surgem as categorias dialogicidade e intersubjetividade como condicionantes do desenvolvimento da esfera pública enquanto lócus da Gestão Social (Cançado et al., 2015).

A democracia deliberativa enfatiza o valor dos processos dialógicos capazes de gerar consensos buscando superar o antagonismo entre participação e representação. Ao acrescentar à democracia o adjetivo "deliberativa", o intuito foi reforçar o caráter de decisão após discussão, essa é a forma de tomada de decisão dentro da esfera pública (Cançado et al., 2015).

Cançado et al. (2015) revelam que a percepção dos autores do campo da Gestão Social sobre a racionalidade como categoria teórica parte do consenso em relação à hegemonia da racionalidade utilitária nas relações sociais. Porém, tais autores podem ser divididos em três linhas (Cançado et al., 2015): Equilíbrio entre as racionalidades, linha que argumenta que a dimensão econômica deve ser integrada, compreendendo 
ação e reflexão, subjetividade e objetividade, criatividade e instrumentalização; Subordinação da lógica instrumental, a qual defende que a lógica instrumental deve ser subordinada a outras lógicas, tais como lógicas sociais, políticas, culturais e ecológicas, pautando-se na racionalidade substantiva; Agir comunicativo, linha que apresenta o agir comunicativo de Habermas como a racionalidade inerente à gestão social. Apresentando elementos conceituais que democratizam as relações na sociedade por meio da linguagem como meio para o entendimento.

Os conceitos de dialogicidade e intersubjetividade são interdependentes por natureza. A dialogicidade é entendida como o diálogo em sentido amplo, onde há a possibilidade de comunicação por todos os participantes. A intersubjetividade complementa a dialogicidade, pois é a capacidade de compreensão do diálogo. Segundos os autores, intersubjetividade é a condição de participação ativa no diálogo, entendendo e se fazendo entender (Cançado et al., 2015).

Ainda a respeito da esfera pública, algumas publicações mais recentes ampliam a discussão em torno dessa categoria. Mesmo em organizações privadas, porém coletivas e democráticas (pelo menos em sua gênese), como cooperativas e empreendimentos da economia solidária (Cançado, 2016) e organizações da sociedade civil organizada (nonprofit) (Cançado\& Pozzebon, 2016) podem ser encontrados elementos inerentes à gestão social. Essas organizações, apesar de não serem públicas no sentido estrito do termo, pois possuem donos (sempre no plural), também buscam o bem comum por meio da tomada de decisão coletiva. Nesse sentido apresentam possibilidades de desenvolvimento da gestão social. Outros estudos estão em curso para melhor delimitar essa esfera pública ampliada.

Por fim, a categoria emancipação é entendida e sintetizada por Cançado et al. (2015) como livrar-se da tutela de alguém, libertar-se, buscar autonomia. Essa categoria teórica da Gestão Social está baseada em assumir sua autonomia (Chauí, 2011).

Complementando a aproximação teórica, a dialética negativa de Adorno (1984) representa a inter-relação entre IBC e Emancipação na esfera pública. A dialética negativa adorniana pode ser entendida como uma dialética sem síntese. Ou seja, tese e antítese sem síntese. Essa relação mostra a interdependência orgânica entre o desenvolvimento do Interesse Bem Compreendido e da Emancipação. Sempre na perspectiva do tipo ideal weberiano.

Por fim, os autores fazem a proposição de uma agenda de pesquisa para o campo da Gestão Social com quatro tópicos que sintetizamos da seguinte forma: Desenvolvimento de Interorganizações e Comunidades de Prática, com o objetivo de desenvolver caminhos para "incentivar" a constituição de Interorganizações e de Comunidades de Prática, preferencialmente de forma complementar; Primeiro paradigma para a Gestão Social, com o objetivo de construir o primeiro paradigma para a Gestão Social e demonstrar que a Gestão Social é multiparadigmática; Escalaridade da Gestão Social, com o objetivo de identificar as possibilidades de escalaridade da Gestão Social com relação à participação direta e indireta e identificar a possibilidade de uso de tecnologias da informação e comunicação para participação direta no âmbito da Gestão Social; Modelo de Análise para identificar a Gestão Social, com o objetivo de aprimoramento metodológico, criando ferramentas e mecanismos para sua utilização em diferentes organizações de forma a verificar suas possibilidades de Gestão Social. Avaliamos que este trabalho se inscreve em alguns tópicos da Agenda de Pesquisa, em especial o segundo e o quarto, uma vez que busca demonstrar a característica multiparadigmática da Gestão Social com a proposta de um modelo de análise fundamentado em Max Weber.

\section{ReSENHA ANALÍTICA}

Nos relatos sobre a experiência iugoslava, o jovem Celso Furtado testemunha um momento histórico de rearranjo da ordem internacional, essa nova ordem do pós-guerra polariza os países e impacta na cultura das nações. As brigadas de trabalho voluntário tiveram início em meados dos anos 1940 e duraram até meados dos anos 1980 (governo Marechal Tito). 
Nametak (2016), pesquisador do Instituto de História de Sarajevo, analisa o papel dessas ações de trabalho juvenil no processo de transformação da sociedade iugoslava. Segundo o pesquisador, a evidência mais marcante desta época é a existência ainda hoje de inúmeras instalações que foram construídas durante esse período. As ferrovias foram as construções mais significativas (três no total, somando 422 quilômetros), mas, as brigadas voluntárias também trabalharam na construção de rodovias, um porto, uma hidrelétrica, uma siderúrgica, assentamentos de mineração entre outras infraestruturas menores, nestes casos, trabalhavam auxiliando o exército, além de fundar a cidade de Novi Travnik, no centro geográfico da atual Bósnia e Herzegovina.

Nametak (2016), cita um trecho de uma entrevista em que o Marechal Josip Broz Tito fala sobre a especificidade fundamental das brigadas:

"Eu, é claro, nunca pensei que o efeito mais importante nas brigadas de trabalho fosse, por assim dizer, o trabalho em si. Eu sempre disse em primeiro lugar sobre seu caráter político-educacional. Eu enfatizei que era uma participação coletiva na construção de uma forma particularmente significativa de educação de jovens, incluindo a aquisição de autogestão e conhecimento" (Nametak 2016, p. 439)

Embora também tenha ocorrido recrutamento compulsório (em substituição do serviço militar), a ampla maioria dos jovens eram voluntários que se dispunham a trabalhar dois meses por ano. As universidades também estavam envolvidas, os estudantes de Engenharia, por exemplo, tinham avaliações relacionadas com seus trabalhos nas brigadas (Springer, 1947). Em meados de 1948, o número de jovens inscritos era de 257.000, que representavam $82 \%$ dos jovens iugoslavos mais os voluntários de outros países. A propaganda para atrair os jovens destacava o sentido político-educacional das brigadas. O objetivo era "criar um novo homem", o novo homem era superior ao velho paradigma de homem, vivia mais saudável, era mais instruído e, portanto, mais capaz de arcar com o ônus de construir uma nova sociedade. Era o desenvolvimento cultural, dando origem a algo concreto e útil (Nametak, 2016)..

Segundo Furtado (2014), naquela época, a expressão "cortina de ferro" começou a fazer parte do cotidiano e da curiosidade de jovens de ambos os lados. Em 1944, aos 24 anos, no Rio de Janeiro, após seu retorno da guerra como segundo tenente da Força Expedicionária Brasileira, o jovem Celso Furtado imaginava a possibilidade de conhecer a União Soviética, especialmente a Rússia, pois tinha interesse em conhecer como funcionava a planificação econômica. Nessa época, pelos motivos políticos que a caracterizavam, não foi possível realizar a viagem para a Rússia, mas quando surgiu a oportunidade de conhecer o leste europeu, foi prontamente aproveitada. A decisão de inscrever-se na Brigada Internacional do Trabalho foi tomada em Paris, no início do Verão de 1947, durante as férias do doutorado. "Mesmo para quem está na França ou na Inglaterra, o outro lado da Europa - au-delà du rideau de fer, conservava algo de misterioso: As opiniões dos viajantes são contraditórias, os fatos são contestados, as notícias são controvertidas" (Furtado, 2014, p. 321). Celso Furtado integrou uma brigada de duzentos e cinquentas indivíduos, organizada entre pessoas que iriam participar do I Festival da Juventude da Tchecoslováquia, festival com ênfase no intercâmbio cultural entre os jovens dos "dois lados da Europa". Celso chama a atenção para o fato de que, embora a viagem tenha sido organizada na França, encontravam-se oito diferentes nacionalidades entre seus componentes. Ele é um observador participante desse encontro e relata que:

Além das brigadas ocidentais, os países eslavos da Europa centro-oriental: Bulgária, Polônia, Iugoslávia e Tchecoslováquia também se fizeram representar por verdadeiras brigadas de entusiasmo. [...] Por toda parte espalhavam o fogo de sua esperança com suas canções: representam um mundo cheio de forças novas. Foi essa a humanidade que rejuvenesceu as ruas respeitáveis da velha Praga (Furtado, 2014, p. 297).

Depois de desfrutar da hospitalidade boêmia de Praga, o jovem Celso segue com o grupo no trem rumo à Iugoslávia, suas impressões vão sendo registradas no decorrer da viagem, seja descrevendo a paisagem, o ambiente de novas amizades com situações engraçadas ou tecendo elucubrações variadas sobre a economia. Chegando lá, sua brigada somou-se "a um exército de jovens trabalhadores de mais de cem mil 
indivíduos" (Furtado, 2014, p. 327). O acampamento ficava na região central da Bósnia “onde as montanhas alternam com bosques exuberantes entrecortados de pequenos cursos d'água”" (Furtado, 2014, p. 328).

\begin{abstract}
No acampamento grandes barracas de madeira já nos esperavam construídas. Um leito de tábuas, duas ou três mantas; quase conforto. Ao lado um rio, adiante uma fonte, além as macieiras carregadas de frutos. Outras brigadas estavam acampadas na mesma região: búlgaros, ingleses, gregos, iugoslavos [...] As cidades apresentam sinais de profunda devastação: É a herança da guerra, mas também uma febre intensa de reconstrução. Os iugoslavos, quase se pode dizer, partem do marco zero (Furtado, 2014, pp. 323-324).
\end{abstract}

Como dito na introdução, esta análise busca responder as questões: Quais características, que hoje são atribuídas a Gestão Social, são possíveis identificar na experiência e na prática relatada por Celso Furtado na Iugoslávia? Qual o ethos da ação? Ao apresentarmos, portanto, fragmentos do relato de Furtado, intenciona-se sintetizar a experiência iugoslava à medida que se destacam características que, a nosso ver, estão inscritas nos parâmetros apresentados sobre Gestão Social. Como colocado por Cançado et al. (2015), as características da Gestão Social são tipos ideais weberianos, têm caráter analítico, buscam a organização das ideias sobre o fenômeno e coexistem na realidade. Primeiramente, a categoria Interesse Bem Compreendido:

\begin{abstract}
Os iugoslavos eram um povo de analfabetos, divididos por lutas fratricidas, cujo trabalho alimentava os banqueiros alemães, franceses e ingleses. As bombas e as forças alemãs operaram o milagre de sua união nacional. $\mathrm{O}$ ardor da luta despertou-os para o trabalho. E pela primeira vez os frutos desse trabalho se tornaram acessíveis àqueles que o realizam. Os iugoslavos, maravilhados, entregam-se à colheita desses frutos. [...] O denominador que os une a todos é o desejo de trabalhar para a construção de um mundo livre de guerras, do medo e da miséria. Essa mocidade já não pensa no futuro em termos de felicidade pessoal: em "vencer", em "fazer fortuna". A tragédia que todos viveram foi suficiente para evidenciar que não há felicidade pessoal onde não há segurança e justiça social. [...] Não se pode deixar de admirar a maturidade que apresentam esses jovens já temperados pela luta. Todos encaram o futuro como uma batalha a vencer. A conquista da paz é o objetivo comum, a ser conquistado na luta de cada dia. O contato direto com essa mocidade conforta pelo ardor que comunica e choca pela complexidade dos problemas que suscita. Nada de meias palavras ou soluções líricas para a vida. Todos pensam em criar condições de prosperidade e paz para seus povos (Furtado, 2014, p. 312-325, p. 296).
\end{abstract}

O Interesse Bem Compreendido emergiu, nesse caso, de uma população historicamente marginalizada e submetida à violência ostensiva. A população uniu-se para um objetivo comum, o recomeço. A felicidade pessoal associa-se à prosperidade e paz social, os resultados que já começavam a aparecer nutriam a responsabilidade compartilhada e a solidariedade, remetendo à ideia de uma continuidade latente, que fica aparente no relato na forma de solidariedade sincrônica e diacrônica, ou seja, solidariedade com as atuais e futuras gerações.

A Iugoslávia é um país mobilizado para o trabalho. Tem-se mobilizado países para a guerra, para o fanatismo religioso ou político. [...] A mobilização do povo iugoslavo não visa diretamente a nenhum desses objetivos. Trabalha-se simplesmente para civilizar o país. Para transformá-lo de nação mais atrasada da Europa em povo progressista e culto. (Furtado, 2014, p. 309).

Avançando em relação à categoria Esfera Pública, argumentamos que Celso Furtado dá elementos que nos permitem analisar duas dimensões dessa categoria, que chamaremos aqui de dimensão global e dimensão local da esfera pública. Ambas as dimensões formam redes adequadas para a comunicação de conteúdos, com efervescentes fluxos comunicacionais interligados. A dimensão global é acessada pelo jovem intelectual por meio da leitura e colaboração com jornais e revistas nacionais e internacionais. Vale dizer que seu primeiro emprego foi durante a graduação no Rio de Janeiro, na imprensa, como auxiliar de redação da Revista da Semana. Lá traduzia e revisava textos, logo começou escrever crônicas e ensaios, bem como fazer reportagens, como a cobertura da visita de Orson Welles ao Brasil. Da Europa, o jovem Celso acompanhava diferentes opiniões e arregimentações de intelectuais pelo mundo por meio de revistas como Realidad (Argentina) e Chemins du Monde (França), das quais era leitor, e ainda outras onde também era colaborador, como o jornal anarquista Panfleto, do Rio de Janeiro, para o qual escreveu os artigos sobre o festival da juventude na Tchecoslováquia, a Omladinska Pruga na Iugoslávia, entre outros. Celso faz análises de conjuntura e traça 
contornos do que, com cautela, pode-se chamar de "opinião pública" da época. Segundo o autor, a pergunta generalizada era "Que atitude tomar, que fazer em face da crise?”. Mostra-se crítico à passividade da geração que permitiu ou até mesmo "estimulou a catástrofe", bem como a ideólogos de um retorno ao passado, críticos radicais da civilização técnica. O fluxo comunicacional que Furtado incorpora na esfera pública global faz contraponto com a opinião pública conservadora, busca a superação da ideologia cética na luta contra o fascismo. Diz o autor:

O fascismo é avesso a criatividade [...] A nova integração buscada pelo fascismo terá necessariamente de quebrar os sistemas de controle existentes para impor o seu poderoso mecanismo de coerção. Daqui a necessidade dentro do fascismo de fazer desaparecer todas as formas vivas e criadoras de organização social para substituí-las por um imenso mecanismo de controle unificado. O fascismo como ideologia totalitária e totalitarismo político pressupõe um amplo desenvolvimento de técnica. Funda-se um formidável mecanismo de propaganda. Sua mística se dirige à necessidade profunda de segurança individual. É nessa necessidade de segurança que o fascismo funda sua psicologia de massas (Furtado, 2014, p. 304).

É desapontante a forma de ceticismo que diz que o mal está nas entranhas mesmo de nosso sistema de vida. Sentimos que é preciso fazer alguma coisa para não sermos tragados, mas não temos ânimo de fazer essa alguma coisa [...] É nesse sentido que a inteligência fracassada do período de antes da guerra pretende exercer a sua ação negativa nos dias de hoje. A nova geração que lhes dê a resposta (Furtado, 2014, p. 279).

A dimensão local da esfera pública é representada pelo fluxo comunicacional propiciado pelo intercâmbio cultural nos festivais e no convívio diário com os amigos e nas comunidades de prática. Abaixo, a primeira citação descreve o local onde ocorrem as ações, Celso apresenta como a rotina do acampamento propiciava diferentes momentos para encontros ociosos e lúdicos. Na segunda citação o autor realiza uma análise sociológica do "ambiente de revolução psicológica" em que se percebe envolvido.

Após as seis horas de trabalho, um banho de fonte. E após o almoço, toda a tarde livre para descanso. À beira do rio as macieiras dão uma sombra convidativa. Organizam-se grupos para debater ideias. À noite a brigada se reúne para o fogo de campo. A visita de elementos de outros grupamentos torna mais festivo o ambiente, danças folclóricas, cantos, histórias, um outro elemento apresenta qualquer coisa de exótico, uma dança oriental, um samba brasileiro... (Furtado, 2014, p. 238).

Num ambiente de revolução psicológica, o homem singular deixa em parte de existir. A massa, que aparece como estado psicológico por toda parte, absorve-o quase completamente. Tomemos como exemplo a juventude iugoslava: Por toda parte se encontram brigadas de jovens trabalhadores. Seu entusiasmo é contagiante. Poderá um jovem do país marchar contra essa maré? Se todos os seus colegas se inscrevem para trabalhar voluntariamente, como poderá ele negar-se? Não se criará uma atmosfera de antipatia ao seu redor? É evidente que essa forma de coerção psicológica se exerce amplamente num país como a Iugoslávia (Furtado, 2014, p. 311).

Num ambiente de revolução psicológica, o homem singular deixa em parte de existir. A massa, que aparece como estado psicológico por toda parte, absorve-o quase completamente. Tomemos como exemplo a juventude iugoslava: Por toda parte se encontram brigadas de jovens trabalhadores. Seu entusiasmo é contagiante. Poderá um jovem do país marchar contra essa maré? Se todos os seus colegas se inscrevem para trabalhar voluntariamente, como poderá ele negar-se? Não se criará uma atmosfera de antipatia ao seu redor? É evidente que essa forma de coerção psicológica se exerce amplamente num país como a Iugoslávia (Furtado, 2014, p. 311).

O compartilhamento de poder decisório no âmbito dos acampamentos é um indicador da valorização do diálogo e da formação de consensos. Contudo, a autonomia relatada ocorria sob uma complexidade que Furtado não perdia de vista, uma vez que a economia política das repúblicas soviéticas e sua planificação econômica despertavam a curiosidade do jovem cientista há algum tempo, de modo que a categoria democracia deliberativa só pode ser mobilizada se percebida como subsidiada pelo Estado iugoslavo. A começar do guichê em Paris, onde se inscreveu na brigada.

Apareci numa agência num boulevard central de Paris, uma jovem muito polida encheu-me de informações: 'Desde o momento que o senhor cruzar a fronteira da Iugoslávia todas as suas despesas ficarão a cargo do governo federal, inclusive o transporte. O senhor visitará algumas das principais cidades do país, inclusive Belgrado...'. A fila era grande e o tempo corria. Fui dando meu nome e saindo (Furtado, 2014, p. 321). 
Entre Paris e a Bósnia existe uma ampla articulação de instituições singulares, para levar a cabo a construção de uma infraestrutura de base (a ferrovia) articulam-se diferentes organizações, com multipolaridade nas relações de poder e natureza híbrida, que se aproximam por objetivos comuns buscando integração. São as interorganizações.

A estrada de ferro onde eu ia trabalhar era um empreendimento e uma realização da juventude. A nova estrada de ferro corta essa zona antes abandonada, mas de grande importância para o futuro industrial do país (Furtado, 2014, p. 324).

Em relação às três linhas da categoria racionalidade, como apresentam Cançado et al. (2015), a primeira, do equilíbrio entre racionalidades, pode ser percebida quando Furtado (2014, p. 384) faz a defesa da civilização técnica, "mesmo sob a ameaça fascista constante ou enchendo de tédio quem tem excesso de ócio". A técnica, diz Furtado (2014), consegue pelo menos dar uma oportunidade de vida, de educação e de independência ao maior número.

Na França uma das respostas reacionárias à crise veio com o discurso de 'luta contra a máquina e defesa do artesanato'. Negação da modernidade, nacionalismo do atraso, defesa das características do espírito francês contra a invasão técnica. [...] A técnica é mais do que uma condição que se impõe a nós; é a forma e o sentido de nossa cultura. As deficiências do conhecimento se superam com um conhecimento maior, e não com o retorno à ignorância (Furtado, 2014, p. 284).

O trabalho espontâneo fundamenta-se numa racionalidade substantiva, o fim não é o lucro individual ou a subsistência. Aqui, o equilíbrio da lógica instrumental com outras lógicas pode ser identificado em situações motivadas por valores humanistas em atitudes de vanguarda, como argumenta Celso.

O conjunto do trabalho era organizado e liderado por jovens iugoslavos cabendo a cada batalhão se organizar e dirigir por si mesmo. O trabalho é completamente espontâneo, e nisto está o segredo de seu rendimento (Furtado, 2014, p. 324).

A terceira linha, a racionalidade comunicativa, está interligada com outras categorias, como dialogicidade e intersubjetividade. Celso fala inglês e francês e está inserido num ambiente de intenso intercâmbio cultural, testemunha o encontro de jovens da Europa ocidental e oriental, onde há uma busca de entendimento no sentido amplo, da compreensão do sentido linguístico ao contexto, busca-se entender e fazer-se entender.

No segundo dia de viagem havia feito boa camaradagem. Apareceu uma jovem com um banjo e pôs todo mundo para cantar. A minha vez chegou inexoravelmente: Um "zamba", dizia a jovem, o Brasil é a terra do "zamba”. [...] Quando souberam que eu era brasileiro, me bombardearam de perguntas: "Como vivem os jovens no Brasil, que organizações de juventude há, que fazem, que pensam..." (Furtado, 2014, p. 322).

O agrupamento do qual Celso fazia parte recebeu a missão de construir o alicerce de uma ponte. Tal dinâmica de interação tem características típicas das comunidades de prática, local onde ocorre a conciliação de saberes e deliberações. A forma como se dá a organização do trabalho no acampamento é descrita por Furtado (2014) da seguinte maneira:

A alvorada é às cinco da manhã, nesse horário os responsáveis pela cozinha e pela inspeção higiênica já estão em atividade. Antes das seis a brigada marcha para o trabalho, às nove e meia, descanso para lanche; às doze, após seis horas de trabalho, suspensão das atividades. [...] As mulheres se entregam com todo ardor ao trabalho, marcadas às vezes por contusões, a face manchada de vermelho pelo sol e sempre alegres [...] e mais tarde ainda nos querem lavar e passar a roupa como se este fosse um trabalho menos fatigante (Furtado, 2014, p. 238).

Por fim, Furtado (2014) argumenta que a luta contra o fascismo está inscrita na tradição marxista, que também intenciona a busca de autonomia, livrar-se da tutela do patrão. Esse é o pano de fundo da emancipação, a construção de um futuro norteado pela autorrealização humana por meio do trabalho não alienado e da criatividade. "A explicação para a revolução que se opera na Iugoslávia é essencialmente psicológica, aqueles jovens acreditam que a salvação do mundo está em abolir da face da terra a miséria e a ignorância" (Furtado, 2014, p. 326). A natureza do Estado e a forma de organização da sociedade diferem dos países ocidentais como França e Inglaterra, avalia o jovem Celso. "A tendência será para a valorização 
do trabalho manual, o nivelamento dos salários, a elevação do nível de vida e a divulgação de formas de aproveitamento do ócio. Em outras palavras, o socialismo" (Furtado, 2014 p. 302).

Fala-se muito na Tchecoslováquia dos privilégios auferidos aos operários mineiros. A resposta dada pelo governo é que a reconstrução do país está acima de tudo, cabendo aos seus principais promotores a maior parcela de estímulo (Furtado, 2014, p. 301).

A seguir apresentamos o quadro síntese dessa análise. Nele as categorias da Gestão Social são relacionadas com os relatos de Celso Furtado e desdobradas em "forma" (aspectos institucionais) e "espírito" (aspectos culturais) da Gestão Social.

Quadro 1 - Síntese Analítica

\begin{tabular}{|c|c|c|c|}
\hline $\begin{array}{l}\text { Categoria da } \\
\text { Gestão Social }\end{array}$ & \begin{tabular}{|l} 
Relato de \\
Celso \\
Furtado
\end{tabular} & $\begin{array}{l}\text { Forma da Gestão } \\
\text { Social }\end{array}$ & $\begin{array}{l}\text { Espírito } \\
\text { da gestão } \\
\text { Social }\end{array}$ \\
\hline $\begin{array}{l}\text { Interesse Bem } \\
\text { Compreendido }\end{array}$ & $\begin{array}{l}\text { União } \\
\text { nacional e } \\
\text { solidariedade } \\
\text { internacional } \\
\text { entre jovens }\end{array}$ & $\begin{array}{l}\text { Frutos do } \\
\text { trabalho } \\
\text { acessiveis àqueles } \\
\text { que o realizam } \\
\text { Compartilhamento } \\
\text { de poder } \\
\text { deliberativo }\end{array}$ & $\begin{array}{l}\text { Não há } \\
\text { felicidade } \\
\text { pessoal } \\
\text { onde não } \\
\text { há } \\
\text { segurança } \\
\text { e justiça } \\
\text { social } \\
\end{array}$ \\
\hline Esfera Pública & $\begin{array}{l}\text { Correntes de } \\
\text { opiniăo }\end{array}$ & $\begin{array}{l}\text { Diversidade e } \\
\text { democratizaçấo } \\
\text { das Mídias } \\
\text { Espaços de } \\
\text { convivência }\end{array}$ & $\begin{array}{l}\text { Superação } \\
\text { da } \\
\text { ideologia } \\
\text { cética na } \\
\text { luta } \\
\text { contra o } \\
\text { fascismo e } \\
\text { promoção } \\
\text { da paz } \\
\text { social }\end{array}$ \\
\hline Emancipação & $\begin{array}{l}\text { Revolução } \\
\text { psicológica }\end{array}$ & $\begin{array}{l}\text { Realização } \\
\text { humana } \\
\text { Aproveitamento } \\
\text { do tempo livre }\end{array}$ & $\begin{array}{l}\text { Desejo de } \\
\text { trabalhar } \\
\text { para a } \\
\text { construção } \\
\text { de um } \\
\text { mundo } \\
\text { livre de } \\
\text { guerras, } \\
\text { do medo, } \\
\text { da miséria } \\
\text { e da } \\
\text { ignorância }\end{array}$ \\
\hline
\end{tabular}

Avaliamos que foi possível demostrar que é possível encontrar nos relatos de Celso Furtado aspectos que são contemporaneamente abordados por diferentes correntes teóricas sobre Gestão Social.

Em relação à categoria Interesse Bem Compreendido, a "união nacional e a solidariedade internacional entre jovens" têm pelo menos duas formas institucionais interligadas, aqui apontamos para uma econômica outra política. As "correntes de opiniões" na Esfera Pública estão presentes na mídia e no agir comunicativo cotidiano. A Emancipação é pragmática, deseja-se um futuro possível, não transcendente, por meio do trabalho não alienado e da criatividade.

Para esta análise, o conjunto dos princípios morais destacados na coluna Espírito do Quadro 1 representam o ethos da experiência iugoslava e coadunam com o paradigma da Gestão Social.

Concluímos que o espírito da Gestão Social é como em Weber, o ethos que orienta a ação social. Não há ascetismo calvinista ou laico no ethos das ações relatadas por Furtado (2014) a "mola auto propulsora" é uma 
austeridade progressista. $\mathrm{Na}$ ética protestante, Max Weber ressalta o papel dos motivos irracionais para a ação ascética, de negação do mundo. O ethos da Gestão Social é imanente, de afirmação do mundo, está no devir.

Aristóteles disse que o Homem é um animal político. Pois bem, se houver algo "irracional” na austeridade progressista, talvez seja pelo fato de o ser humano ser um animal gregário.

\section{BibLIOGRAFIA}

Adorno, T. W. (1984) Dialética negativa (J. María Ripalda, Trad.). Madrid: Taurus.

Chauí, M. (2011) Cultura e democracia: o discurso competente e outras falas. 13. ed. São Paulo: Cortez, 368p.

Cançado, A. C., Pozzebon, M. (2016) Social management: the potential contribution of a Brazilian research tradition to the international nonprofit debate. In: ISTR's 12th International Conference: The Third Sector in Transition: Accountability, Transparency, and Social Inclusion.Stockholm. Anals of ISTR's 12th International Conference: The Third Sector in Transition: Accountability, Transparency, and Social Inclusion. Stockholm. v. 1. 1-16.

Cançado, A. C, Pereira, J. R., Tenório, F. G. (2015). Gestão Social: epistemologia de um paradigma. 2 ed. Curitiba, Editora CRV.

Cançado, A. C. (2016) Gestão Social e Economia Solidária para além do mimetismo: outra gestão é possível? Revista de Economia Solidária, 10(1), 18-43.

D’Aguiar, R. F. (2014) Anos de Formação (in) Furtado, C. Anos de Formação:1938-1948, o jornalismo, o serviço público, a guerra, o doutorado. 1 ed. Rio de Janeiro, Contraponto. Centro Internacional Celso Furtado de Política para o Desenvolvimento.7-37.

Furtado, C. (2014a) Obra Autobiográfica: A fantasia organizada; A fantasia desfeita; os ares do mundo.1 ed. São Paulo, Companhia das Letras.

Furtado, C. (2014b) Anos de formação:1938-1948, o jornalismo, o serviço público, a guerra, o doutorado. 1 ed. Rio de Janeiro, Contraponto. Centro Internacional Celso Furtado de Política para o Desenvolvimento.

Guerreiro Ramos, A. (1981) A nova ciência das organizações: uma reconceituação da riqueza das nações. Rio de Janeiro, FGV.

Habermas, J. (2003). Mudança Estrutural da Esfera Pública. Rio de Janeiro, Tempo Brasileiro.

Hartmann, F. C. (2014). A Forma e o "Espírito" do Capitalismo em Max Weber. Em Tese, 11(1), 30-44.

Krištofić, S. B. (org). (2017). Omladinske Radne Akcije - Dizajn Ideoligije. Umjetnička organizacija Kultura umjetnosti, Zagreb. Recuperado de: http://kulturaumjetnosti.blogspot.hr

Nametak. M. (2014) Uloga omladinskih radnih akcija u stvaranju socijalističkoga društva. ČSP, br. 3, 437-452. Recuperado de: https://www.google.com/search?q=Nametak.+M.+(2014)+Uloga+omladinskih+radnih+ak cija+u+stvaranju+socijalisti\%C4\%8Dkoga+dru\%C5\%A1tva.+\%C4\%8CSP\%2C+br.+3.\%2C+437.-452.\&rl z=1C1GGRV_enBR751BR751\&oq=Nametak.+M.+(2014)+Uloga+omladinskih+radnih+akcija+u+stvara nju+socijalisti\%C4\%8Dkoga+dru\%C5\%A1tva.+\%C4\%8CSP\%2C+br.+3.\%2C+437.-452.\&aqs=chrome..69 i57.816j0j8\&sourceid $=$ chrome\&ie $=U$ TTF-8

Oliveira, V. A. R., Cançado, A. C., \& Pereira, J. R. (2010). Gestão social e esfera pública: aproximações teóricoconceituais. Cadernos EBAPE.BR, 8(4), 613-626.

Schluchter, W. (2011). Paradoxos da modernidade: cultura e conduta na teoria de Max Weber. São Paulo, Editora Unesp.

Springer, Z. (1947). Building the New Nation (Part 2) Construction of the railway line Samac - Sarajevo. Recuperado de http://www.cosy.sbg.ac.at/ Zzspri/lifestories/1947SmSr/47SamSar.html

Tenório, F. G. (2008). Critérios para a avaliação de processos decisórios participativos deliberativos na implementação de políticas públicas. Anais do Encontro De Administração Pública e Governança, Salvador, BA, Brasil, XXXII.

Weber, M. (2009). A ética protestante e o espírito do capitalismo. São Paulo, Martin Claret. 


\section{Anexo 1:}

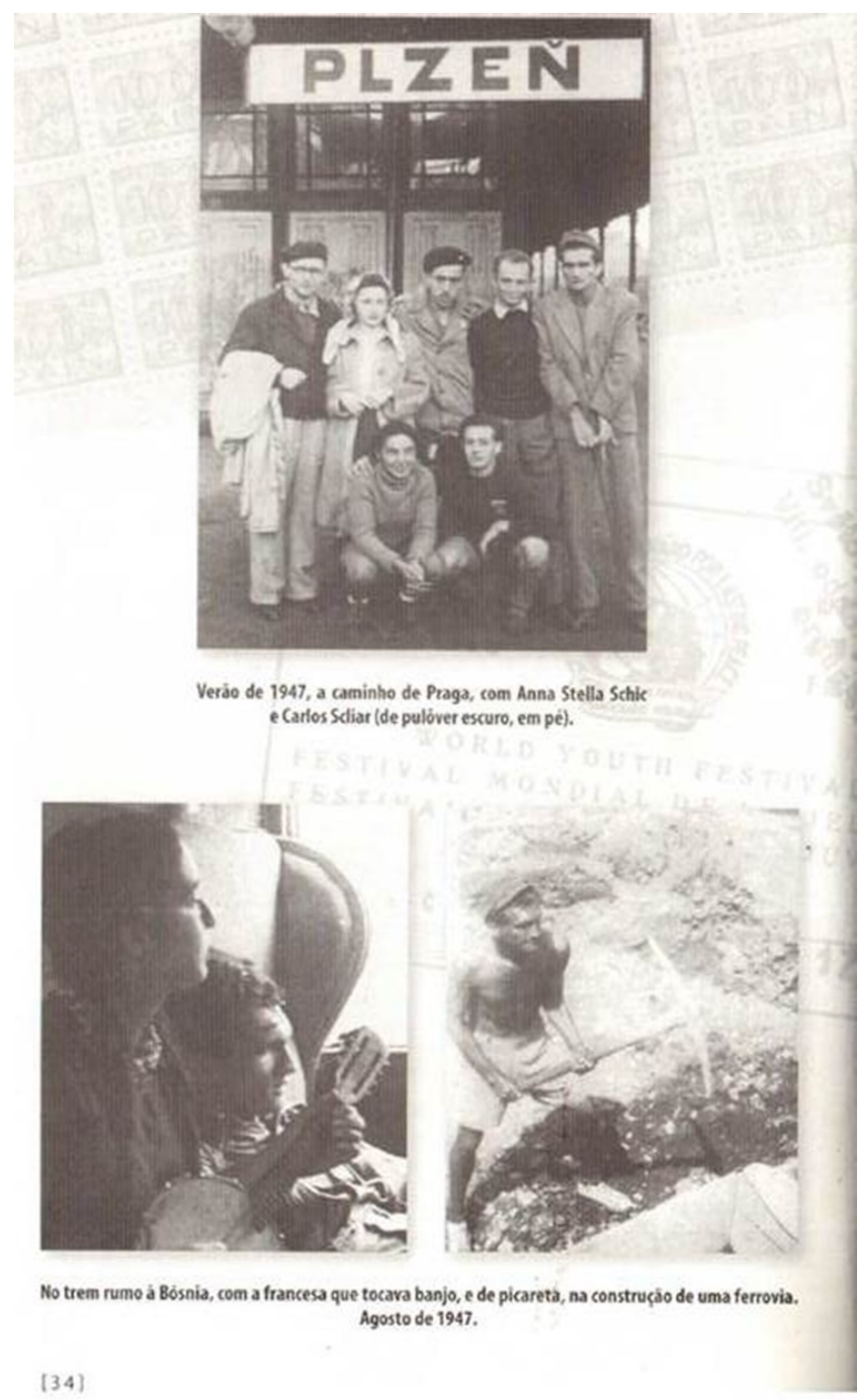

Fonte: Furtado, C. (2014b) Anos de formação:1938-1948, o jornalismo, o serviço público, a guerra, o doutorado. $1^{a}$ ed. Rio de Janeiro, Contraponto. Centro Internacional Celso Furtado de Política para o Desenvolvimento.

\section{BY-NC-ND}

